\title{
Assessment of the effect of calcium on the anti-inflammatory activity of etoricoxib in albino rats
}

\author{
Sonali Naringrekar ${ }^{1 *}$, Jayesh Mamtora $^{2}$
}

\author{
${ }^{1}$ Department of Pharmacology, Banas Medical College and Research Institute, Gujarat, India \\ ${ }^{2}$ DGO, Private Practitioner, Palanpur, Gujarat, India
}

Received: 16 April 2021

Accepted: 10 May 2021

\author{
*Correspondence: \\ Dr. Sonali Naringrekar, \\ Email: researchguide86@gmail.com
}

Copyright: $\odot$ the author(s), publisher and licensee Medip Academy. This is an open-access article distributed under the terms of the Creative Commons Attribution Non-Commercial License, which permits unrestricted non-commercial use, distribution, and reproduction in any medium, provided the original work is properly cited.

\begin{abstract}
Background: It would be worthwhile to investigate if it is possible to obtain an anti-inflammatory effect with a lower dose of etoricoxib after it has been combined with calcium, the effect of which is equivalent to higher dose of etoricoxib. Hence the aim was to study effect of calcium and calcium gluconate on the anti-inflammatory activity of etoricoxib.

Methods: Animals were distributed in five groups each group containing six rats. Experiments were conducted between 9:00 to 16:00 hours. All animal procedures were performed in accordance with the recommendations for proper care and use of laboratory animal. The doses of drugs employed in the study were based upon the human dose after conversion to that of rat.

Results: The results of present study indicate that calcium gluconate $(50 \mathrm{mg} / \mathrm{kg}$ ) combined with etoricoxib $(5 \mathrm{mg} / \mathrm{kg})$ possesses significant anti-inflammatory property both in acute and subacute models of inflammation which was comparable to that of etoricoxib $(8 \mathrm{mg} / \mathrm{kg})$.

Conclusions: From the present study it is concluded that calcium gluconate $(50 \mathrm{mg} / \mathrm{kg})$ possesses an antiinflammatory activity. Lower dose of etoricoxib $(5 \mathrm{mg} / \mathrm{kg})$ if combined with calcium gluconate $(50 \mathrm{mg} / \mathrm{kg})$ can produce significant anti-inflammatory effect. The advantages of such combined preparations are obviously a reduction in the dose of etoricoxib that could still produce significant anti-inflammatory action and a possible protection against COX -2 inhibitor induced prothrombotic events. It is worthwhile to evaluate such preparations through clinical trials.
\end{abstract}

Keywords: Albino rat, Anti inflammatory agent, Calcium, Etoricoxib

\section{INTRODUCTION}

Inflammation is fundamentally a protective response of the body. It is a complex biological response of vascular tissues to harmful stimuli. It is the body's natural reaction to protect itself from infection and foreign substances. Without inflammation, wounds would never heal and infections would go unchecked. In the practice of medicine, the importance of inflammation is that it can sometimes be inappropriately triggered or poorly controlled, and is thus the cause of tissue injury in many disorders. ${ }^{1,2}$
Inflammation continues to be area of great interest for research probably due to non availability of a safer and more effective anti-inflammatory agent. The conventional nonselective non steroidal anti-inflammatory drugs (NSAIDs) like aspirin, diclofenac etc possess side effects like gastrointestinal disturbances, ulcerations, impairment of renal functions and hypersensitivity reactions. ${ }^{3}$ The newer COX-2 selective agents such as celecoxib and etoricoxib etc retain the anti-inflammatory effect characteristic of NSAIDs with a marked increase in gastrointestinal tolerability as compared to classic non selective ones. But even these agents show cardiotoxic, 
renotoxic and hepatotoxic side effects. Hence the search for alternatives or adjuvants to these drugs is still going on in an attempt to produce an ideal anti-inflammatory drug. 4

In recent years increased understanding of the inflammatory mechanism and the mediators involved has led to the development of newer anti-inflammatory agents like monoclonal antibodies e.g. natalizumab and antagonists of inflammogens e.g. tumor necrosis factoralpha (TNF-alpha) blocking agents like infliximab, etanercept etc. ${ }^{5}$ Interestingly several other drugs like minocycline, ascorbic acid, calcium salts e.g. calcium dobesilate, calcium hydroxide and calcium pentosan polysulfate have been reported to possess antiinflammatory property.

Earlier calcium chloride was advocated for the treatment of urticaria, acute edema, pruritus and erythema. Calcium carbonate and calcium gluconate were used for the treatment of insect stings and calcium hydroxide to suppress periapical inflammation in dental practice. These reports indicate that calcium salts possess antiinflammatory property. Interaction of calcium supplementation and NSAIDs has shown a protective effect on colorectal neoplasia. ${ }^{6}$

A study has reported that sub-anti-inflammatory dose of calcium gluconate $(5 \mathrm{mg} / \mathrm{kg})$ co-administered with subanti-inflammatory doses of aspirin $(54 \mathrm{mg} / \mathrm{kg})$ exhibited significant anti-inflammatory activity in acute as well as subacute models of inflammation. The present study is intended to find if similar interaction is seen between calcium gluconate and selective COX-2 inhibitor etoricoxib. ${ }^{7}$ A study has also reported that calcium gluconate $(5 \mathrm{mg} / \mathrm{kg})$ has pro-inflammatory activity when administered alone. In another study locally applied calcium neither inhibited edema nor reduced inflammatory signs. Similarly, calcium salts failed to prevent effusion across capillary endothelial membrane. In another study, calcium gluconate has been reported to produce pancreatitis in cats. ${ }^{8}$

Current study was aimed at answering a few important questions and issues. If calcium is able to enhance effect of etoricoxib as it has been shown to enhance nonselective NSAID, aspirin, it might be possible to use calcium to enhance anti-inflammatory effect of etoricoxib. The study was done to investigate the effect of calcium gluconate on the anti-inflammatory activity of etoricoxib.

Etoricoxib is the NSAID of choice in patients who are intolerant to gastrointestinal side effects of other NSAIDs like aspirin. Cardiovascular toxicity like prothrombotic events like myocardial infarction, renal toxicity are the major side effects of COX-2 inhibitors. ${ }^{9}$ It would be worthwhile to investigate if it is possible to obtain an anti-inflammatory effect with a lower dose of etoricoxib $(60 \mathrm{mg})$ after it has been combined with calcium, the effect of which is equivalent to higher dose of etoricoxib (90 mg). ${ }^{10}$ Such a combination would achieve equivalent anti-inflammatory effect and at the same time would be less likely to be associated with complications of higher doses of etoricoxib. This combination of etoricoxib and calcium gluconate would be beneficial in patients with following clinical conditions e.g. rheumatoid arthritis, osteoarthritis and gouty arthritis etc.

\section{METHODS}

Current study was carried out in 5 groups of Wistar rats (6 rats/group) of either sex for anti inflammatory tests at department of pharmacology and central animal house, Bharati Vidyapeeth deemed university medical college, Sangli.

Male and female (non pregnant) Wistar rats weighing (150-270 grams) were used for the study. They were housed under standardized conditions (temperature $25^{\circ} \mathrm{C}$, relative humidity $60 \%$ and 12 hour light/dark cycle). They had access to standard pellet diet and water ad. libitum. Animals were distributed in five groups each group containing six rats. Experiments were conducted between 9:00 to 16:00 hours. All animal procedures were performed in accordance with the recommendations for proper care and use of laboratory animal. The doses of drugs employed in the study were based upon the human dose after conversion to that of rat.

Table 1: Drug treatment schedule for antiinflammatory studies (acute and subacute).

\begin{tabular}{|lll|}
\hline $\begin{array}{l}\text { Group } \\
\text { no. }\end{array}$ & $\begin{array}{l}\text { No. of } \\
\text { rats }\end{array}$ & Treatment \\
\hline $\mathbf{1}$ & 6 & Control $(1 \%$ gum acacia $)$ \\
\hline $\mathbf{2}$ & 6 & Etoricoxib $(8 \mathrm{mg} / \mathrm{kg})$ \\
\hline $\mathbf{3}$ & 6 & Etoricoxib $(5 \mathrm{mg} / \mathrm{kg})$ \\
\hline $\mathbf{4}$ & 6 & $\begin{array}{l}\text { Calcium gluconate }(5 \mathrm{mg} / \mathrm{kg}) \text { and } \\
\text { etoricoxib }(5 \mathrm{mg} / \mathrm{kg})\end{array}$ \\
\hline $\mathbf{5}$ & 6 & $\begin{array}{l}\text { Calcium gluconate }(50 \mathrm{mg} / \mathrm{kg}) \text { and } \\
\text { etoricoxib }(5 \mathrm{mg} / \mathrm{kg})\end{array}$ \\
\hline
\end{tabular}

\section{Drugs}

The clinical doses of various drugs were converted to rat equivalent doses. The volume of drug administered orally was $<1 \mathrm{ml} / 100 \mathrm{gm}$ of rat. The drug requirement for each animal was calculated by weight and the required amount of drug was dissolved in appropriate volume of the vehicle. All the drugs were freshly prepared on the day of the experiment and used the same day. All the drugs and chemicals were obtained from Pratik enterprises. Etoricoxib: was suspended in $1 \%$ gum acacia. Calcium gluconate: was dissolved in distilled water. Carrageenan $1 \%$ solution was made distilled water. Gum acacia $1 \%$ solution was made with distilled water. Ether, spirit and betadine were also used in experiments. Surgical 
materials used in experiment were scalpel, scissor, suture material, artery forcep, cotton, etc.

Acute inflammation was produced by injecting carrageenan in the hind paw of Wistar rats and subacute inflammation by implanting sterile cotton pellets subcutaneously as described below.

\section{Carrageenan induced rat paw edema}

Test drugs were administered orally according to the body weight 30 minutes before injecting $0.05 \mathrm{ml}$ of $1 \%$ of sterile carrageenan in normal saline into subplantar region of the left hind paw. A mark was made at the left ankle joint. Contra-lateral limb received equal volume of saline. Paw volume upto the ankle joint was measured in drug treated \& untreated group. The edema volume was measured by mercury displacement with the help of a plethysmograph before carrageenan injection and 0,30 min and $1,3,5$ hours, $5^{\text {th }}$ day and $14^{\text {th }}$ day after injecting carrageenan. The difference between 0 hour and subsequent readings was considered as edema volume.

Percentage reduction in edema was calculated using the below mentioned formula:

$$
\% R E=\frac{\text { Mean edema CG }- \text { Mean edema TG }}{\text { Mean edema CG }} \times 100
$$

Where \% RE is percentage reduction in edema, $\mathrm{CG}$ is control group and TG is treated group.

\section{Cotton pellet induced granuloma}

This method is widely used to study the exudative and proliferative phases of inflammation. Autoclaved cotton pellets $(5 \mathrm{mg}$ ) were used. Under ether anaesthesia, pellets were inserted subcutaneously through skin incision in the axilla of the animals. Aseptic precautions were taken throughout the experiment. Drugs treatment was started 2 hours after cotton pellet implantation and continued for 5 consecutive days. Control group received $1 \%$ gum acacia suspension for the same duration as the drug. On the $6^{\text {th }}$ day, under anaesthesia granulomas were removed surgically and skin was sutured. The granulomas were dried for 24 hours at $60^{\circ} \mathrm{C}$ and the dry weights were determined. The weight of granulomatous tissue formed was calculated by subtracting initial weight from the final dry weight of cotton pellets and percentage protection by the drug was calculated. Mean granuloma dry weight for the various groups were calculated and expressed as $\mathrm{mg} / 100$ gm body weight using the following formula. The percentage inhibition of granuloma dry weight was calculated using formula:

$$
\% \mathrm{GID}=\frac{(\mathrm{Tc}-\mathrm{Tt})}{\mathrm{Tc}} \times 100
$$

Where \%GID is percentage inhibition of granuloma dry weight Tc is dry weight of granuloma in control group and $\mathrm{Tt}$ is dry weight of granuloma in treated groups.

\section{Statistical analysis}

Statistical analysis was carried out using one way ANOVA (analysis of variance) for significance between groups for percentage inhibition of carrageenan induced edema. Data was expressed as mean \pm SD. The level of significance between individual groups was detected using unpaired " $t$ " test for percentage inhibition of edema. For all tests, effects with a probability of $\mathrm{p}<0.05$ were considered to be significant.

\section{RESULTS}

\section{Acute studies}

Carrageenan induced paw edema in group 5 and group 2: the calcium gluconate $(50 \mathrm{mg} / \mathrm{kg})$ combined with etoricoxib (5 mg/kg) (group 5) did not differ from the corresponding values in the etoricoxib $(8 \mathrm{mg} / \mathrm{kg}$, group 2 ), indicating the effective dose of calcium gluconate (50 $\mathrm{mg} / \mathrm{kg}$ ). There was no significant difference in the means of paw volume at $1 \mathrm{hr}, 3 \mathrm{hr}$ and $5 \mathrm{hr}$ in etoricoxib (8 $\mathrm{mg} / \mathrm{kg}$ ) (group 2) and etoricoxib (5 mg/kg) combined with calcium gluconate $(50 \mathrm{mg} / \mathrm{kg}$ ) (group 5) indicating that calcium gluconate $(50 \mathrm{mg} / \mathrm{kg})$ enhanced antiinflammatory activity of etoricoxib $(5 \mathrm{mg} / \mathrm{kg})$.

Carrageenan induced paw edema in group 4 and group 3, the calcium gluconate $(5 \mathrm{mg} / \mathrm{kg})$ combined with etoricoxib (5 mg/kg) (group 4) did not differ from the corresponding values in the etoricoxib $(5 \mathrm{mg} / \mathrm{kg}$ ) (group $3)$, indicating that calcium gluconate $(5 \mathrm{mg} / \mathrm{kg})$ did not enhance anti-inflammatory activity of etoricoxib (5 $\mathrm{mg} / \mathrm{kg}$ ). There was no significant difference in the means of paw volume at $1 \mathrm{hr}, 3 \mathrm{hr}$ and $5^{\text {th }}$ day in etoricoxib $(5 \mathrm{mg} / \mathrm{kg}$ group 3) and etoricoxib $(5 \mathrm{mg} / \mathrm{kg})$ combined with calcium gluconate ( $5 \mathrm{mg} / \mathrm{kg}$ group 4$)$.

Carrageenan induced paw edema in group 4 and group 2, the calcium gluconate $(5 \mathrm{mg} / \mathrm{kg})$ combined with etoricoxib (5 $\mathrm{mg} / \mathrm{kg}$ ) (group 4) was more than the corresponding values in the etoricoxib $(8 \mathrm{mg} / \mathrm{kg}$ ) (group 2) indicating that calcium gluconate $(5 \mathrm{mg} / \mathrm{kg})$ combined with etoricoxib $(5 \mathrm{mg} / \mathrm{kg})$ did not have anti-inflammatory effect comparable to etoricoxib $(8 \mathrm{mg} / \mathrm{kg})$. There was significant $(\mathrm{p}<0.05)$ difference in means of paw volume at $3 \mathrm{hr}$ and $5 \mathrm{hr}$.

Mean granuloma dry weights in drugs treated groups were significantly lower than the control group indicating significant $(\mathrm{p}<0.05)$ anti-inflammatory property of etoricoxib and etoricoxib combined with calcium gluconate. Etoricoxib $(5 \mathrm{mg} / \mathrm{kg})$ and calcium gluconate (50 mg/kg, group 5) did not show significant difference in granuloma dry weight when compared to etoricoxib (8 $\mathrm{mg} / \mathrm{kg}$ ) (group 2). Etoricoxib (5 $\mathrm{mg} / \mathrm{kg}$ ) and calcium gluconate $(50 \mathrm{mg} / \mathrm{kg}$, group 5) showed significant $(\mathrm{p}<0.05)$ difference in granuloma dry weight when compared to etoricoxib (5 mg/kg, group 3). Etoricoxib (5 $\mathrm{mg} / \mathrm{kg}$ ) and calcium gluconate $(5 \mathrm{mg} / \mathrm{kg}$ ) (group 4) 
showed significant $(\mathrm{p}<0.05)$ difference in granuloma dry weight when compared to etoricoxib ( $8 \mathrm{mg} / \mathrm{kg}$ ) (group 2). Etoricoxib $(5 \mathrm{mg} / \mathrm{kg})$ and calcium gluconate $(5 \mathrm{mg} / \mathrm{kg}$, group 4) did not show significant difference in granuloma dry weight when compared to etoricoxib $(5 \mathrm{mg} / \mathrm{kg}$, group $3)$.

Table 2: Effects of various treatments on carrageenan induced paw edema.

\begin{tabular}{|c|c|c|c|c|c|c|c|}
\hline Time & Group & $\mathbf{N}$ & Mean & Std. deviation & Std. error & $\mathbf{F}$ & P value \\
\hline \multirow{5}{*}{$30 \mathrm{~min}$} & 1 & 6 & 0.416 & 0.204 & 0.083 & \multirow{5}{*}{1.000} & \multirow{5}{*}{0.426} \\
\hline & 2 & 6 & 0.500 & 0.000 & 0.000 & & \\
\hline & 3 & 6 & 0.500 & 0.000 & 0.000 & & \\
\hline & 4 & 6 & 0.500 & 0.000 & 0.000 & & \\
\hline & 5 & 6 & 0.500 & 0.000 & 0.000 & & \\
\hline \multirow{5}{*}{1 hour } & 1 & 6 & 0.916 & 0.204 & 0.083 & \multirow{5}{*}{5.972} & \multirow{5}{*}{$0.002 * *$} \\
\hline & 2 & 6 & 0.500 & 0.000 & 0.000 & & \\
\hline & 3 & 6 & 0.583 & 0.200 & 0.083 & & \\
\hline & 4 & 6 & 0.500 & 0.000 & 0.000 & & \\
\hline & 5 & 6 & 0.666 & 0.258 & 0.105 & & \\
\hline \multirow{5}{*}{3 hours } & 1 & 6 & 1.166 & 0.408 & 0.166 & \multirow{5}{*}{7.839} & \multirow{5}{*}{$0.000 * *$} \\
\hline & 2 & 6 & 0.250 & 0.273 & 0.111 & & \\
\hline & 3 & 6 & 0.583 & 0.204 & 0.083 & & \\
\hline & 4 & 6 & 0.583 & 0.204 & 0.083 & & \\
\hline & 5 & 6 & 0.333 & 0.408 & 0.166 & & \\
\hline \multirow{5}{*}{5 hours } & 1 & 6 & 1.416 & 0.204 & 0.083 & \multirow{5}{*}{45.000} & \multirow{5}{*}{$0.000 * *$} \\
\hline & 2 & 6 & 0.166 & 0.258 & 0.105 & & \\
\hline & 3 & 6 & 0.500 & 0.000 & 0.000 & & \\
\hline & 4 & 6 & 0.500 & 0.000 & 0.000 & & \\
\hline & 5 & 6 & 0.166 & 0.258 & 0.105 & & \\
\hline \multirow{5}{*}{5 days } & 1 & 6 & 0.666 & 0.258 & 0.105 & \multirow{5}{*}{15.972} & \multirow{5}{*}{$0.000 * *$} \\
\hline & 2 & 6 & 0.000 & 0.000 & 0.000 & & \\
\hline & 3 & 6 & 0.083 & 0.204 & 0.083 & & \\
\hline & 4 & 6 & 0.083 & 0.204 & 0.083 & & \\
\hline & 5 & 6 & 0.000 & 0.000 & 0.000 & & \\
\hline \multirow{5}{*}{14 days } & 1 & 6 & 0.333 & 0.258 & 0.105 & \multirow{5}{*}{10.000} & \multirow{5}{*}{$0.000 * *$} \\
\hline & 2 & 6 & 0.000 & 0.000 & 0.000 & & \\
\hline & 3 & 6 & 0.000 & 0.000 & 0.000 & & \\
\hline & 4 & 6 & 0.000 & 0.000 & 0.000 & & \\
\hline & 5 & 6 & 0.000 & 0.000 & 0.000 & & \\
\hline
\end{tabular}

$* \mathrm{P}<0.05$ is significant, $* * \mathrm{P}<0.01$ is highly significant, group 1-control $1 \%$ gum acacia, group 2-etoricoxib $8 \mathrm{mg} / \mathrm{kg}$, group 3-etoricoxib 5 $\mathrm{mg} / \mathrm{kg}$, group 4-etoricoxib $5 \mathrm{mg} / \mathrm{kg}$ and calcium gluconate $5 \mathrm{mg} / \mathrm{kg}$, group 5- etoricoxib $5 \mathrm{mg} / \mathrm{kg}$ and calcium gluconate $50 \mathrm{mg} / \mathrm{kg}$.

Table 3: Effects of various treatments on granuloma dry weight.

\begin{tabular}{|c|c|c|c|c|c|c|}
\hline Group & $\mathbf{N}$ & Mean & Std. deviation & Std. error mean & $\mathbf{F}$ & P value \\
\hline 1 & 6 & 23.00 & 0.894 & 0.365 & \multirow{5}{*}{180.433} & \multirow{5}{*}{$0.000 * *$} \\
\hline 2 & 6 & 13.33 & 0.516 & 0.211 & & \\
\hline 3 & 6 & 15.50 & 0.548 & 0.224 & & \\
\hline 4 & 6 & 15.17 & 0.753 & 0.307 & & \\
\hline 5 & 6 & 14.17 & 0.753 & 0.307 & & \\
\hline
\end{tabular}

$* \mathrm{P}<0.05$ is significant, $* * \mathrm{P}<0.01$ is highly significant

\section{DISCUSSION}

The results of present study indicate that calcium gluconate $(50 \mathrm{mg} / \mathrm{kg})$ combined with etoricoxib (5 $\mathrm{mg} / \mathrm{kg}$ ) possesses significant anti-inflammatory property both in acute and subacute models of inflammation which was comparable to that of etoricoxib $(8 \mathrm{mg} / \mathrm{kg})$. A review of literature reveals that in different models of inflammation, calcium salts like calcium dobesilate, calcium hydroxide and calcium pentosan polysulfate possess anti-inflammatory property. Calcium pentosan sulfate suppresses neutrophil accumulation, NO activity and IL-6 activity in inflamed rat subcutaneous air-pouch model. Calcium chloride is recommended for the 
treatment of urticaria, acute edema, pruritus and erythema. Calcium carbonate and calcium gluconate have been used to treat insect stings. Calcium hydroxide has been used in dental practice to suppress periapical inflammation. ${ }^{11}$

Table 4: Percentage inhibition of dry weight of granuloma.

\begin{tabular}{|lll|}
\hline Group & $\begin{array}{l}\text { Mean granuloma dry } \\
\text { weight mg/100gm body } \\
\text { weight (Mean+SEM) }\end{array}$ & \% inhibition \\
\hline $\mathbf{1}$ & $23.00+/-0.365$ & - \\
\hline $\mathbf{2}$ & $13.33+/-0.211$ & 42.04 \\
\hline $\mathbf{3}$ & $15.50+/-0.224$ & 32.60 \\
\hline $\mathbf{4}$ & $15.17+/-0.307$ & 34.08 \\
\hline $\mathbf{5}$ & $14.17+/-0.307$ & 39.14 \\
\hline
\end{tabular}

The mechanism of anti-inflammatory action of calcium cannot be proposed on the basis of present findings. However several mechanisms have been proposed in earlier reports. Piller has speculated that calcium dobesilate reduced the number of circulating monocytes and also blocked the action of macrophage in order to suppress inflammation. It has also been shown that calcium dobesilate can suppress platelet aggregatingfactor production in endothelial cells in a dose-dependent manner. The above mechanisms may play a role in the anti-inflammatory activity of calcium gluconate too. ${ }^{6,12}$

The other proposed anti-inflammatory mechanisms of calcium salts include the precipitant action of calcium on a cement substance and enhanced superoxide anions scavenging through increased activity of superoxide dismutase, peroxidase, glutathione peroxidase and glutathione reductase which are reported to be increased by calcium glubionate. It is well-known that such enzymes suppress inflammation. It is not known whether calcium salt like calcium gluconate have a property similar to that of calcium glubionate, which could explain their anti-inflammatory action. ${ }^{13,14}$

In some smooth muscles, calcium through the calciumsensitive potassium channels, can lead to hyperpolarization. If this is also true for the vascular smooth muscles, then calcium can produce vasodilatation. In fact, calcium has been reported to produce vasodilatation by stabilizing the cell membrane. Due to vasodilatation the interendothelial cell gaps may be reduced, leading to decreased effusion, which is one of the events of inflammation. ${ }^{15}$

In one study it is shown that calcium is required for postengulfment responses of phagocytes such as the antiinflammatory response that normally accompanies engulfment of apoptotic cells. In one study antiinflammatory effect of calcium carbonate was observed. The reduction of oxidative stress may explain the antiinflammatory effect. Zemel and Sun studied the effect of high calcium diet in the form of calcium carbonate and dairy products on inflammation markers. It was found that calcium carbonate markedly decreased inflammatory cytokine gene expression in adipose tissue with significant suppression of TNF- $\alpha$, IL- 6 and MCP-1 (monocyte chemoattractant protein-1). High calcium diet also significantly suppressed plasma MDA (malondialdehyde) and inhibited NADPH oxidase expression and ROS production. ${ }^{16}$ The inhibitory effect of calcium on oxidative stress was due to suppression of circulating 1, 25 dihydroxycholecalciferol which is a regulator of ROS production in murine and human adipocytes.

Calcium gluconate effectively inhibited ligature placement induced periodontitis and related alveolar bone loss. Experimental periodontitis (EPD) induced increases in MPO, IL- 1 beta and TNF- $\alpha$ were significantly and dose dependently inhibited by calcium gluconate, suggesting that calcium gluconate inhibited the cytotoxic effects of polymorphonuclear neutrophils (PMNs).

On the contrary, in earlier reports; locally applied calcium chloride neither inhibited edema formation nor reduced inflammatory signs when injected along with the inflammogen in rats. In the study of Cates et al the intravenous infusion of calcium gluconate in cats enhanced inflammation and increased the permeability of the pancreatic duct to large dextran molecules that had been perfused through it and were detected in the portal venous blood. ${ }^{10}$

The results of the present study favour the combined use of etoricoxib and calcium gluconate, if the present findings could be extrapolated to clinical situations. The advantages of such combined preparations are obviously a reduction in the dose of etoricoxib that could still produce significant anti-inflammatory action and a possible protection against $\mathrm{COX}-2$ inhibitor induces prothrombotic events. It is worthwhile to evaluate such preparations through clinical trials.

\section{CONCLUSION}

From the present study it is concluded that calcium gluconate $(50 \mathrm{mg} / \mathrm{kg})$ possesses an anti-inflammatory activity. Lower dose of etoricoxib $(5 \mathrm{mg} / \mathrm{kg})$ if combined with calcium gluconate $(50 \mathrm{mg} / \mathrm{kg})$ can produce significant anti-inflammatory effect. The advantages of such combined preparations are obviously a reduction in the dose of etoricoxib that could still produce significant anti-inflammatory action and a possible protection against COX-2 inhibitor induced prothrombotic events. It is worthwhile to evaluate such preparations through clinical trials.

Funding: No funding sources

Conflict of interest: None declared

Ethical approval: The study was approved by the Institutional Ethics Committee 


\section{REFERENCES}

1. Chen L, Deng H, Cui H, Fang J, Zuo Z, Deng J, et al. Inflammatory responses and inflammation-associated diseases in organs. Oncotarget. 2018;9:7204.

2. Anderson JM. Biological responses to materials. Ann Rev Materials Res. 2001;31:81-110.

3. Russell R. Non-steroidal anti-inflammatory drugs and gastrointestinal damage-problems and solutions. Postgrad Med J. 2001;77:82-8.

4. Rayburn ER, Ezell SJ, Zhang R. Anti-inflammatory agents for cancer therapy. Mol Cell Pharmacol. 2009; $1: 29$.

5. LaDuca JR, Gaspari AA. Targeting tumour necrosis factor alpha: New drugs used to modulate inflammatory diseases. Dermatol Clin. 2001;19:61735 .

6. Karnad A, Patil P, Majagi S. Calcium enhances antiinflammatory activity of aspirin in albino rats. Indian J Pharmacol. 2006;38:397.

7. Patil P, Karnad A. Calcium enhances antiinflammatory activity of aspirin in albino rats. Indian J Pharmacol. 2006;38(6):397-402.

8. Sohn KC, Kang SJ, Kim JW, Kim KY, Ku SK, Lee YJ. Effects of Calcium gluconate, a water soluble calcium salt on the collagen-induced DBA/1J mice rheumatoid arthritis. Biomol Ther. 2013;21:290.

9. Kean WF, Buchanan WW. The use of NSAIDs in rheumatic disorders 2005: a global perspective. Inflammopharmacol. 2005;13:343-70.

10. Ong C, Lirk P, Tan C, Seymour R. An evidence-based update on nonsteroidal anti-inflammatory drugs. Clin Med Res. 2007;5:19-34.

11. Lindahl M, Ljungman A, Bruhn R, Hede R, Tagesson C. Calcium ionophore-activated neutrophils prestimulated with endotoxin increase pulmonary arterial pressure and vascular leakage in isolated perfused rat lungs: role of platelet-activating factor. Exper Lung Res. 1991;17:77-89.

12. Piller N. Assessment of the anti-inflammatory action of calcium dobesilate. Effect on macrophages attaching to subcutaneously implanted coverslips in guinea pigs. Arzneimittel-forschung. 1990;40:698700.

13. Willhite CC, Karyakina NA, Yokel RA, Yenugadhati N, Wisniewski TM, Arnold IM, et al. Systematic review of potential health risks posed by pharmaceutical, occupational and consumer exposures to metallic and nanoscale aluminum, aluminum oxides, aluminum hydroxide and its soluble salts. Crit Rev Toxicol. 2014;44:1-80.

14. Soetan K, Olaiya C, Oyewole O. The importance of mineral elements for humans, domestic animals and plants-A review. Afr J Food Sci. 2010;4:200-22.

15. Brozovich F, Nicholson C, Degen C, Gao YZ, Aggarwal M, Morgan KG. Mechanisms of vascular smooth muscle contraction and the basis for pharmacologic treatment of smooth muscle disorders. Pharmacol Rev. 2016;68:476-532.

16. Zemel MB, Sun X. Dietary calcium and dairy products modulate oxidative and inflammatory stress in mice and humans. J Nutr. 2008;138:1047-52.

Cite this article as: Naringrekar S, Mamtora J. Assessment of the effect of calcium on the antiinflammatory activity of etoricoxib in albino rats. Int J Basic Clin Pharmacol 2021;10:683-8. 